\title{
Rituximab therapy for lupus nephritis: A meta-analysis
}

\author{
LEI SHEN $^{1 *}$, XIANGYING LIU ${ }^{2 *}$, CI SUN $^{3}$, GUOYUAN LU ${ }^{1}$, LING ZHOU ${ }^{1}$ and JIANZHONG LI ${ }^{1}$ \\ ${ }^{1}$ Department of Nephrology, The First Affiliated Hospital of Soochow University, Suzhou, Jiangsu 215006; \\ ${ }^{2}$ Department of Nephrology, Suzhou Ninth People's Hospital, Suzhou, Jiangsu 215299; ${ }^{3}$ Department of Nephrology, \\ The Second Affiliated Hospital of Soochow University (The General Hospital of Nuclear Industry, \\ The Sino-France Friendship Hospital), Suzhou, Jiangsu 215004, P.R. China
}

Received March 23, 2021; Accepted July 20, 2021

DOI: 10.3892/wasj.2021.119

\begin{abstract}
The aim of the present study was to assess the clinical efficacy and safety of rituximab (RTX) therapy in the treatment of lupus nephritis by performing a meta-analysis. For this purpose, the PubMed, Embase, Cochrane Library, Chinese Biomedical Literature, China National Knowledge Infrastructure, VIP Information and WANFANG databases were used to identify the eligible studies from January, 2000 to February, 2020. STATA16.0 and Review Manager Version 5.3 software were applied to pool the data. From the results of this search, 37 studies (30 case series and seven controlled trials) involving 1,273 patients were included. In the case series studies, the total remission (TR) rate was $81.9 \%$ (95\% CI, 73.7-88.8\%) and the complete remission (CR) rate was $46.6 \%$ (95\% CI, 36.4-57.1\%). Following treatment with RTX, the systemic lupus erythematosus disease activity index (SLEDAI) of patients with lupus nephritis decreased significantly [mean difference (MD), $-8.91 ; 95 \% \mathrm{CI},-14.10$ to -3.72 , $\mathrm{P}<0.01]$. The level of proteinuria also decreased significantly [standardized mean difference (SMD), $-1.05 ; 95 \%$ CI, -1.28 to $-0.83, \mathrm{P}<0.01]$. On the contrary, the level of serum albumin increased significantly (MD, 6.44; 95\% CI, 4.42-8.45; $\mathrm{P}<0.01$ ). In the controlled trials, both TR and CR were significantly higher than those of the control group (TR: OR, 2.48; 95\% CI, 1.58-3.89; P<0.01; and CR: OR, 2.29; 95\% CI, 1.17-4.49; $\mathrm{P}<0.05)$. Compared with the control group, the SLEDAI of patients in the RTX group decreased significantly (MD, -3.84; $95 \% \mathrm{CI},-5.99$ to $-1.69 ; \mathrm{P}<0.01)$ and the level of proteinuria in the RTX group also decreased significantly (MD, -1.24; 95\% CI, -2.39 to $-0.09 ; \mathrm{P}<0.05)$. At the same time, the level
\end{abstract}

Correspondence to: Dr Ci Sun, Department of Nephrology, The Second Affiliated Hospital of Soochow University (The General Hospital of Nuclear Industry, The Sino-France Friendship Hospital), 1055 Sanxiang Road, Suzhou, Jiangsu 215004, P.R. China

E-mail: 78796940@qq.com

*Contributed equally

Key words: rituximab, lupus nephritis, systemic lupus erythematosus, B lymphocytes, CD20 of serum albumin increased (MD, 0.54; 95\% CI, 0.22-0.86; $\mathrm{P}<0.01)$. There was no difference in the relative risks of the adverse events between the two groups (OR, 0.37; $\mathrm{P}>0.05$ ). On the whole, the findings of the present study demonstrate that RTX exhibits favorable clinical efficacy in the treatment of lupus nephritis, which can significantly reduce the level of proteinuria and SLEDAI, and increase the level of serum albumin. Compared with traditional immunosuppressive therapy (corticosteroids + cyclophosphamide and/or mycophenolate), RTX was more effective in the treatment of lupus nephritis. Additionally, rituximab exhibited good safety.

\section{Introduction}

Systemic lupus erythematosus (SLE) is an autoimmune disease characterized by multi-organ damage. Kidney involvement occurs in up to $60 \%$ of patients with $\operatorname{SLE}(1,2)$. Owing to treatment with corticosteroids and immunosuppressive therapy, the prognosis of patients with lupus nephritis (LN) has markedly improved; however, a large number of patients continue to develop irreversible kidney damage and end-stage renal disease. Therefore, the identification of novel, more effective therapeutic methods with more favorable safety profiles are urgently required.

Hyper-reactive B lymphocytes play a central role in the pathogenesis of $\mathrm{LN}$. The abnormal activation of B lymphocytes produces a large number of pathogenic autoantibodies, which causes disorders in the cellular and humoral immunity and leads to tissue damage. Therefore, B-lymphocyte depletion (BLyD) (3) can result in the significant clinical remission of LN. Another study reported that B lymphocyte stimulators exist in the kidney tubulointerstitium, which can induce pathogenic B lymphocyte migration, leading to sustained kidney injury. However, rituximab (RTX) can deplete B lymphocytes in the kidney tubulointerstitium continuously and achieve BLyD (4).

RTX is a chimeric antibody which binds specifically to the B-cell surface antigen, CD20, an integral membrane protein, which is expressed immature and mature B lymphocytes, but it is not found in early B-cell precursors or plasma cells (5). RTX exerts its effect through three pathways: By binding to $\mathrm{Fc}$ receptor and mediating cell killing through antibody-dependent cellular toxicity, by binding $\mathrm{Clq}$ and activating complement-dependent cytotoxicity and finally, by stimulating the apoptotic pathway (3). 
RTX was the first approved agent for the treatment of relapsed or refractory lymphoma. It has subsequently been used in various autoimmune diseases, including LN $(6,7)$. However, the majority of the studies on RTX in LN are case reports or small clinical studies (as demonstrated below in the Results section). Thus, the present study aimed to assess the clinical efficacy and safety of RTX as a novel immunosuppressive treatment for $\mathrm{LN}$ by performing a meta-analysis of the available literature.

\section{Data and methods}

Sources and searches. The PubMed (https://www.ncbi.nlm. nih.gov), Embase (https://www.embase.com), Cochrane Library (https://www.cochranelibrary.com/), Chinese Biomedical Literature (http://www.sinomed.ac.cn/), China National Knowledge Infrastructure (https://www.cnki.net/), VIP Information (http://lib.cqvip.com/) and WANFANG (https://www.wanfangdata.com.cn) databases were searched using the terms 'rituximab' and 'lupus nephritis' between January, 2000 and February, 2020. The following key words and medical subject heading terms were used: 'Rituximab, rituxan, CD20 antibody, rituximab CD20 antibody, Mabthera, IDEC C2B8 antibody, lupus nephritis, lupus glomerulonephritis, glomerulonephritis lupus, lupus nephritides, systemic lupus erythematosus, SLE, LN'. Studies published in the English or Chinese languages following a literature or database search were included.

Inclusion and exclusion criteria. The following inclusion criteria were used: i) Case series (retrospective case series and prospective case series) or controlled trials [randomized controlled trials (RCTs) and non-RCTs] regarding RTX therapy in patients with $\mathrm{LN}$; ii) availability of data on therapeutic efficacy and safety; iii) availability of data on urinary protein, serum albumin and activity index (SLEDAI) prior to and following treatment; and iv) enrolled patients with a diagnosis of LN disease based on the American College of Rheumatology criteria.

The following exclusion criteria were used: i) Abstracts, reviews, case reports and editorials; ii) animal experiments; iii) inability to extract complete data from the literature; and iv) duplicate reports from the same study.

Data extraction. In total, two investigators performed the screening of the abstracts and identified duplicates by reviewing full articles, determining their eligibility and extracting data independently. A custom Excel sheet was used to collect all relevant data based on the surname of the first author, publication year, case number, age, sex, intervention and outcome characteristics.

Quality evaluation. The quality assessment tool of the Institute of Health Economics (IHE) (https://ihe.ac.bd/) was used in case series studies. The quality of the results was considered acceptable if the score was $>14$. The quality of non-randomized controlled studies was assessed according to the methodological index for non-randomized studies (MINORS) (8) tool. The quality was considered acceptable if the score was $>13$. The JADAD quality scale (9) was used to assess the quality of randomized controlled studies. A score $<3$ was considered low quality, while a score with a range of 4-7 was considered high quality.

Statistical analysis. STATA16.0 and Review Manager Version 5.3 were used to pool the data. The remission rate of the case series was pooled by STATA16.0. Additional data analysis was performed by Review Manager Version 5.3. Homogeneous studies $\left(\mathrm{I}^{2}<50 \%\right)$ were examined by a fixed-effects model to estimate the combined effect. Heterogeneous studies $\left(\mathrm{I}^{2}>50 \%\right)$ were examined by a random-effects model. $\mathrm{P}<0.05$ was considered to indicate a statistically significant difference.

The present study was mainly divided into two parts. The first part was a case series analysis, including prospective and retrospective case studies. The following parameters were analyzed: Total remission rate (TR; complete remission plus partial remission), complete remission rate (CR), proteinuria and SLEDAI. The second part was controlled trial analysis, involving the comparison of the parameters TR, CR, proteinuria, serum albumin and SLEDAI between the RTX and the control groups.

\section{Results}

Characteristics of the included studies. A total of 1,593 publications were searched in total, of which 36 studies involving 1,280 patients were included. These studies comprised 29 case series (10-38) and seven controlled trials (39-45). In total, six trials were published in Chinese, whereas 30 trials were published in English. The patients examined in four trials were children, whereas the remaining 32 trials included adults. The details of these trials are presented in Tables I and SI.

Quality evaluation of the literature. A total of 29 case series were evaluated by the IHE quality assessment tool, all of which met $>14$ criteria and were considered acceptable (10-38). In total, five non-randomized trials were evaluated by the MINORS quality assessment tool, all of which scored $>13$ and were considered acceptable (39-43). Moreover, two randomized trials were evaluated by the JADAD quality scale tool $(44,45)$. The score for the study by Rovin et al $(44)$ was 5 , whereas the score for the study of Zhang et al (45) was 4. Both of them were considered high quality.

Case series with $L N$. The results of the meta-analysis indicated that 28 studies involving 641 patients with LN analyzed clinical remission as an outcome (10-37). The TR was $81.9 \%$ (95\% CI, 73.7-88.8\%; P<0.05; Fig. 1), whereas the CR was 46.6\% (95\% CI, 36.4-57.1\%; P>0.05; Fig. 2).

In total, three case series reported changes in the SLEDAI of patients with $\mathrm{LN}(31,35,36)$. The results indicated that following treatment of the patients with RTX, the SLEDAI decreased significantly [mean difference (MD), $-8.91 ; 95 \% \mathrm{CI}$, -14.10 to $-3.72 ; \mathrm{P}<0.01 ;$ Fig. 3].

In total, six studies reported the levels of proteinuria prior to and following RTX treatment $(13,20,23,25,30,34)$. The data were analyzed and it was shown that the levels of proteinuria in patients with LN were significantly reduced following treatment with RTX [standardized mean difference (SMD), -1.05; 95\% CI, -1.28 to -0.83 ; $<<0.01$; Fig. 4]. 


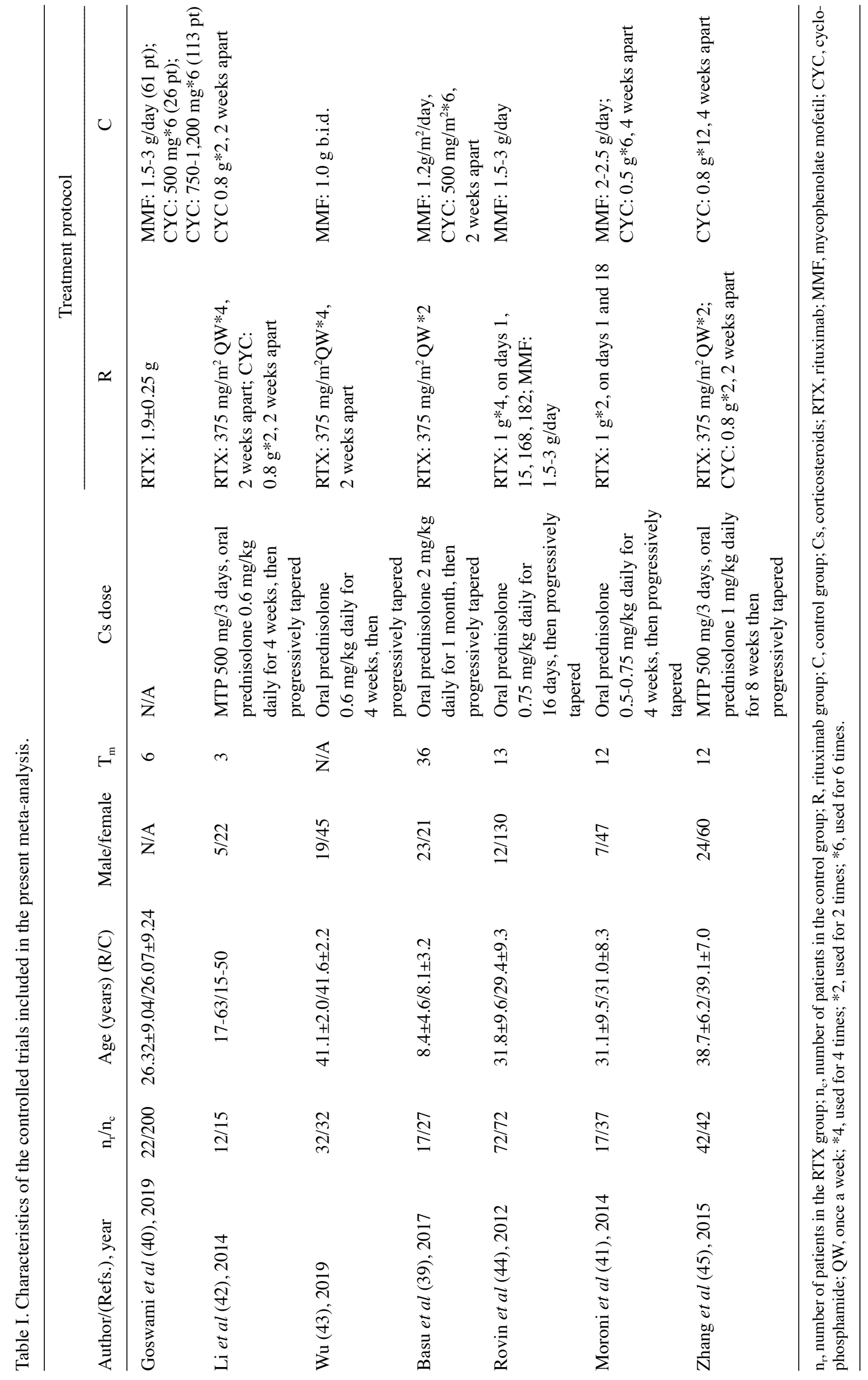




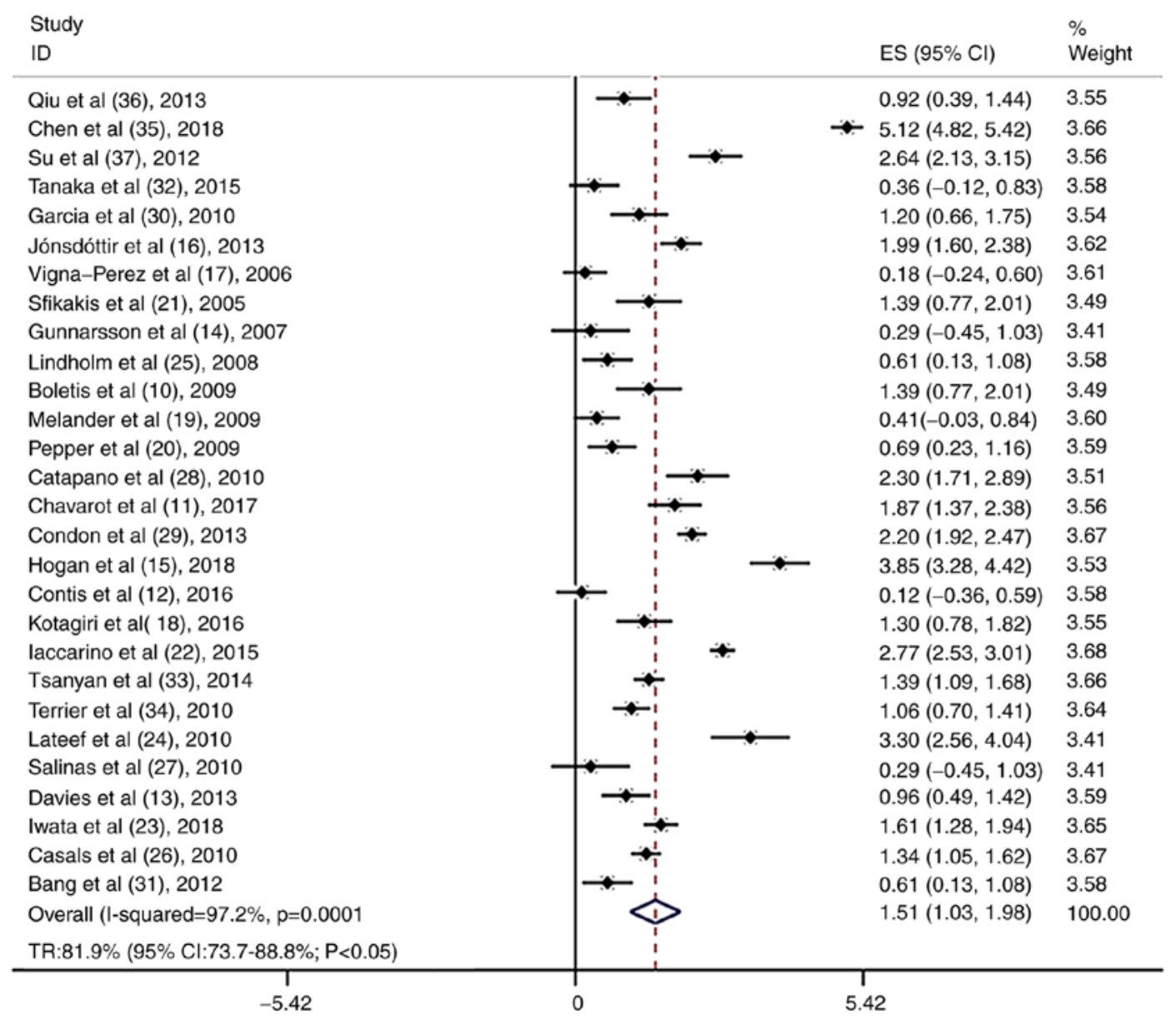

Figure 1. Total remission rate in patients treated with rituximab in the case series trials.

In total, three case series reported serum albumin levels $(13,20,30)$. The results indicated that following treatment of the patients with RTX, the levels of serum albumin were significantly increased (MD, 6.44; 95\% CI, 4.42-8.45; $\mathrm{P}<0.01$; Fig. 5).

Controlled trials with LN. A total of seven controlled trials were included in the statistical analysis, involving a total of 639 patients (RTX group, 214 cases; control group, 425 cases). The treatment regimen for the RTX group was single-drug RTX or corticosteroids plus RTX or corticosteroids plus RTX plus cyclophosphamide (CYC)/mycophenolate mofetil (MMF), while the control group was treated with routine corticosteroids plus CYC, CYC plus MMF or corticosteroids plus CYC plus MMF.

TR and CR were reported in seven control trials (39-45). Following the meta-analysis, it was found that both the TR and CR were significantly higher in the RTX group than in the control group [TR: Odds ratio (OR), 2.48; 95\% CI, 1.58-3.89; $\mathrm{P}<0.01$; Fig. 6; CR: OR, 2.29; 95\% CI, 1.17-4.49; P<0.05; Fig. 7].

In total, five studies compared the SLEDAI $(39,41-43,45)$. It was found that its levels were lower in the RTX group than those of the control group. The results were statistically significant (MD, -3.84, 95\% CI, -5.99-1.69; P<0.01; Fig. 8).

A total of five studies that examined proteinuria were included in the analysis $(40-43,45)$. The results indicated that the levels of proteinuria in the RTX group were lower than those noted in the control group. The differences were statistically significant (MD, -1.24; 95\% CI, -2.39-0.09; $\mathrm{P}<0.05$; Fig. 9).

In total, three studies compared plasma albumin levels and the data indicated that the serum albumin levels in the RTX group were significantly higher than those in the control group (MD, 0.54; 95\% CI, 0.22-0.86; P<0.01; Fig. 10) $(41,42,45)$.

Adverse events. A total of 16 case series involving 188 patients reported adverse reactions following RTX treatment, including $21(11.2 \%)$ patients who developed infusion reactions (10-22,30,36,38). A total of 65 (34.6\%) patients developed mild infections, mainly in the respiratory and urinary system and recovered following treatment. Furthermore, 4 (2\%) patients developed severe infection following RTX treatment and 1 patient died of severe infection; granulocytopenia occurred in $7(3.7 \%)$ patients during treatment; only $1(0.5 \%)$ of the patients developed skin photosensitive reaction following treatment.

A total of four controlled trials reported adverse reactions $(39,40,42,44)$. The data reported in these studies were compared between the RTX and the control groups. No significant differences were noted (OR, 0.37; $\mathrm{P}>0.05$; Fig. 11).

\section{Discussion}

$\mathrm{LN}$ is a severe manifestation of SLE. The treatment of LN can be adjusted by reducing the steroid dose, optimizing 
Study

ID

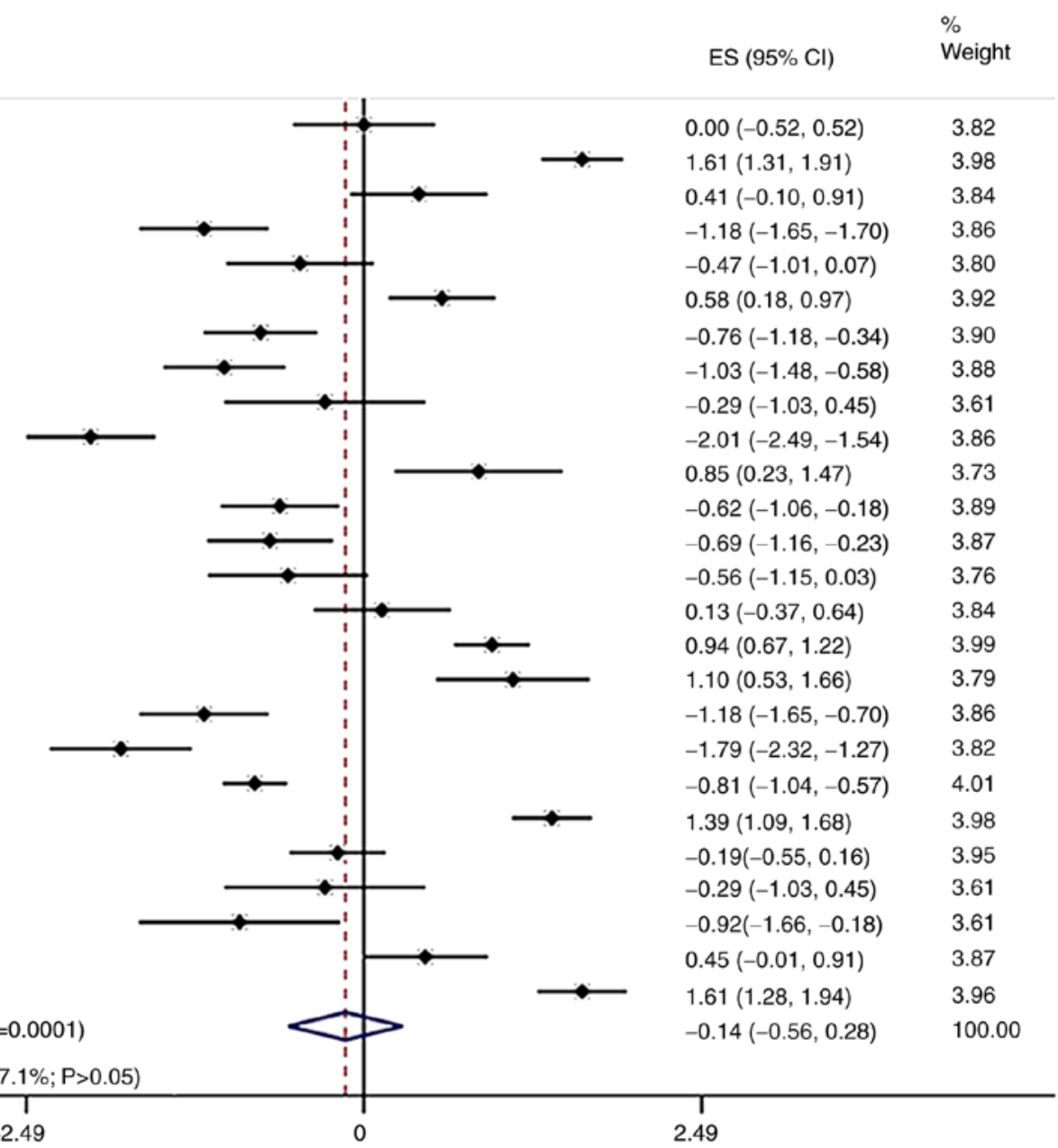

Figure 2. Complete remission rate in patients treated with rituximab in the case series trials.

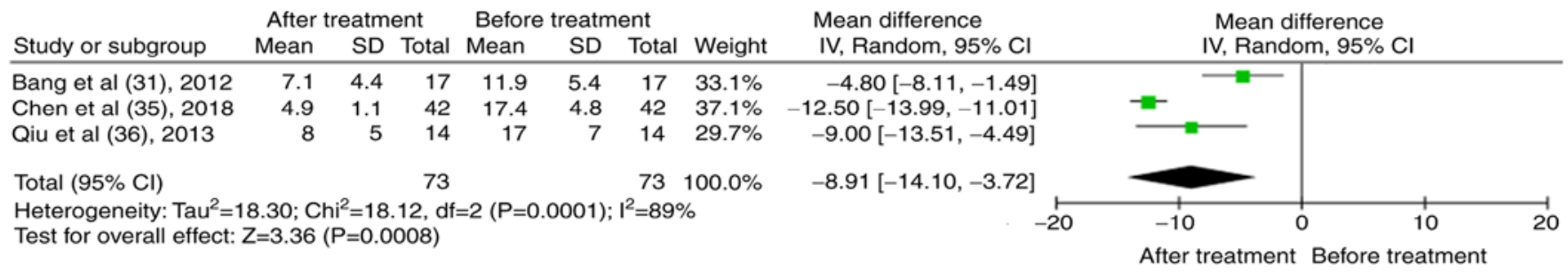

Figure 3. Results of the meta-analysis of the systemic lupus erythematosus disease activity index in patients treated with rituximab in the case series trials.

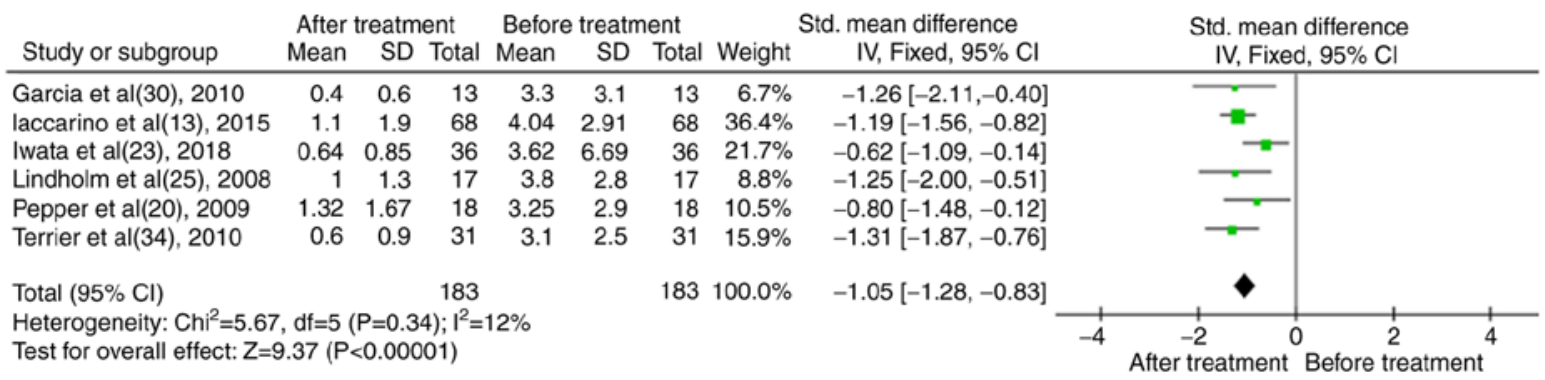

Figure 4. Results of the meta-analysis of proteinuria in patients treated with rituximab in the case series trials.

CYC protocols and introducing new drugs, such as MMF and tacrolimus. The European League against Rheumatism recommendations suggest that $\mathrm{MMF}$ and low-dose CYC are the treatments of choice for the induction of remission and should 


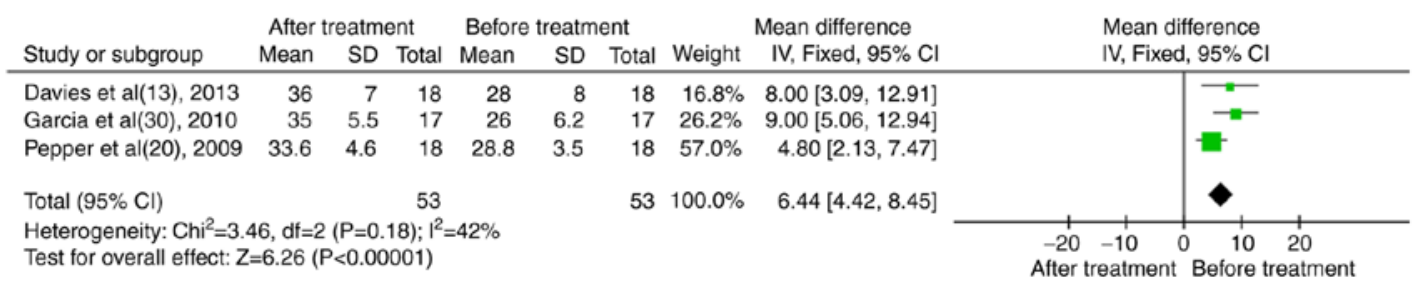

Figure 5. Results of the meta-analysis of serum albumin in patients treated with rituximab in the case series trials.

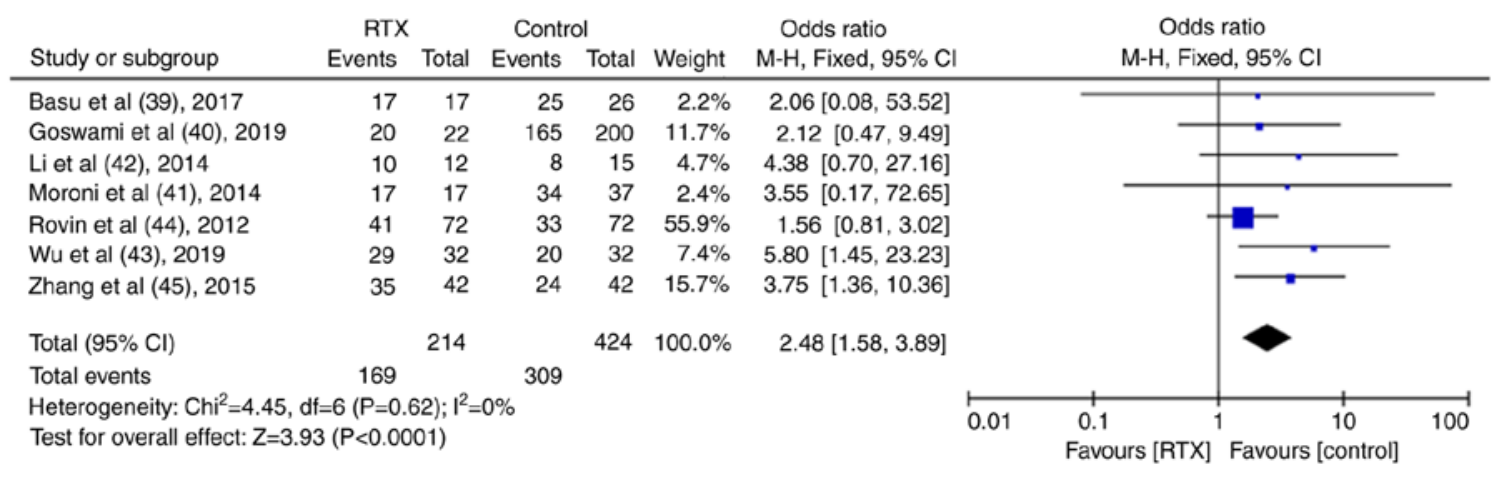

Figure 6. Results of the meta-analysis of the total remission rate in patients treated with rituximab in the controlled trials.

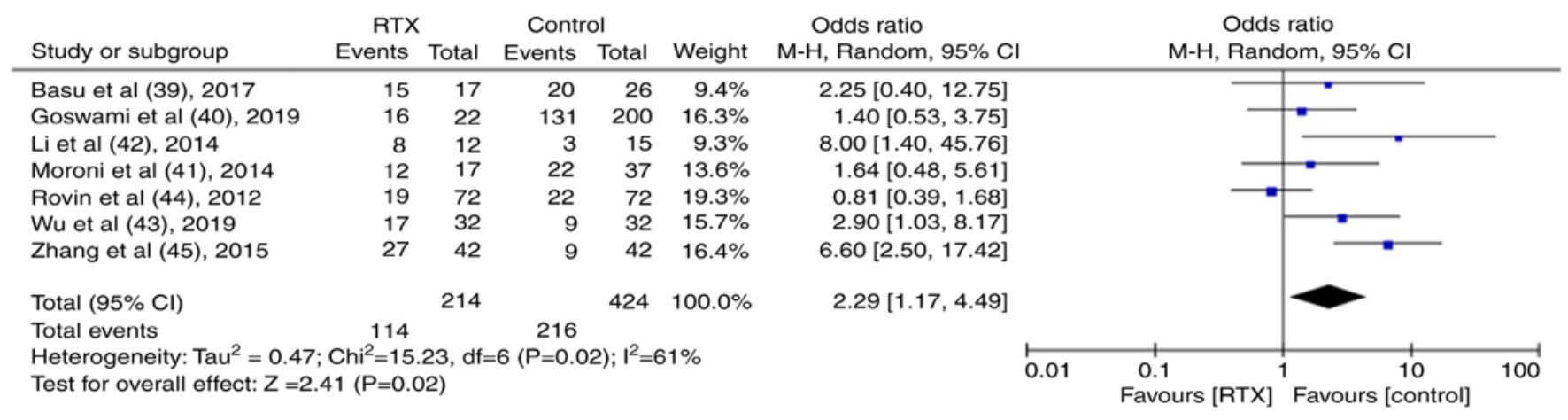

Figure 7. Results of the meta-analysis of the complete remission rate in patients treated with rituximab in the controlled trials.

\begin{tabular}{|c|c|c|c|c|c|c|c|c|c|c|c|}
\hline \multirow{3}{*}{$\begin{array}{l}\text { Study or subgroup } \\
\text { Basu et al (39), } 2017\end{array}$} & \multicolumn{3}{|c|}{ RTX } & \multicolumn{3}{|c|}{ Control } & \multirow[b]{2}{*}{ Weight } & \multirow{2}{*}{$\begin{array}{l}\text { Mean difference } \\
\text { IV, Random, } 95 \% \mathrm{Cl}\end{array}$} & \multirow{2}{*}{\multicolumn{2}{|c|}{$\begin{array}{l}\text { Mean difference } \\
\text { IV, Random, } 95 \% \mathrm{CI}\end{array}$}} & \\
\hline & \multirow{2}{*}{ Mean } & \multirow{2}{*}{$\begin{array}{l}S D \\
2.3\end{array}$} & \multirow{2}{*}{$\begin{array}{r}\text { Total } \\
17\end{array}$} & \multirow{2}{*}{$\begin{array}{r}\text { Mean } \\
8.03\end{array}$} & \multirow{2}{*}{$\frac{\mathrm{SD}}{3}$} & \multirow{2}{*}{$\begin{array}{r}\text { Total } \\
27\end{array}$} & & & & & \\
\hline & & & & & & & $20.3 \%$ & $-2.93[-4.50,-1.36]$ & \multirow[t]{2}{*}{$\longrightarrow$} & & \\
\hline Li et al (42), 2014 & 4.2 & 1.92 & 12 & 8 & 2.23 & 15 & $20.2 \%$ & $-3.80[-5.37,-2.23]$ & & & \\
\hline Wu et al (43), 2019 & 8.02 & 1.2 & 32 & 14.89 & 1.2 & 32 & $22.3 \%$ & $-6.87[-7.46,-6.28]$ & \multirow[b]{2}{*}{$\longrightarrow$} & & \\
\hline Zhang et al (45), 2015 & 4.31 & 1.82 & 17 & 7.69 & 2.28 & 37 & $21.3 \%$ & $-3.38[-4.51,-2.25]$ & & & \\
\hline
\end{tabular}

Figure 8. Results of the meta-analysis of the systemic lupus erythematosus disease activity index in patients treated with rituximab in the controlled trials.

be followed by a maintenance therapy with MMF, azathioprine or calcineurin inhibitors (46). However, Tektonidou et al (47) demonstrated that the incidence of end-stage renal disease has plateaued at $\sim 10 \%$ compared with the increase noted in the 2000s.

The pathogenesis of SLE is complex. It is widely accepted that the abnormal activation of B lymphocytes and the production of a large number of autoantibodies causes immune function disorders $(48,49)$. A previous study reported that among 119 patients with LN, 52.1\% experienced B lymphocyte infiltration in their kidney tissues. The levels of serum creatinine and urea, which are considered indices of kidney tissue activity and chronicity, were significantly increased in patients with B lymphocyte infiltration compared with those without B lymphocyte infiltration (50). An additional study indicated significant improvements in the clinical 


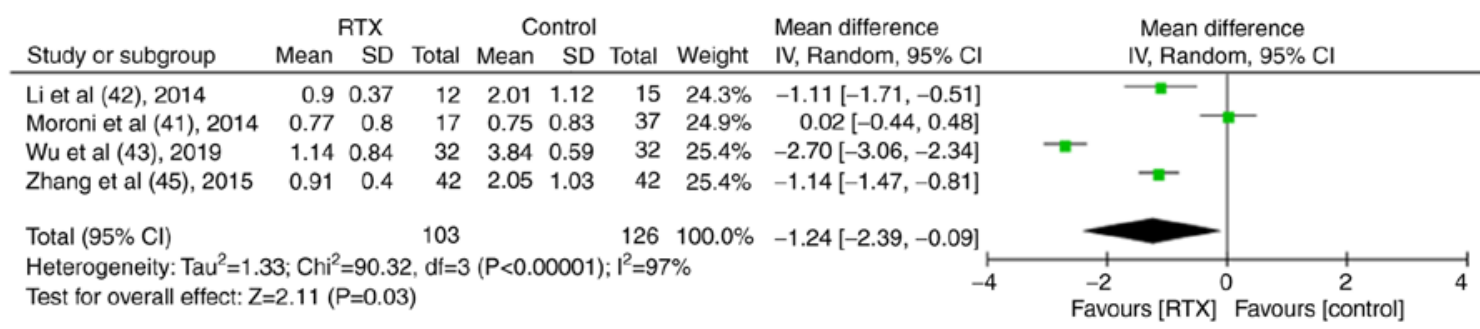

Figure 9. Results of the meta-analysis of proteinuria in patients treated with rituximab in the controlled trials.

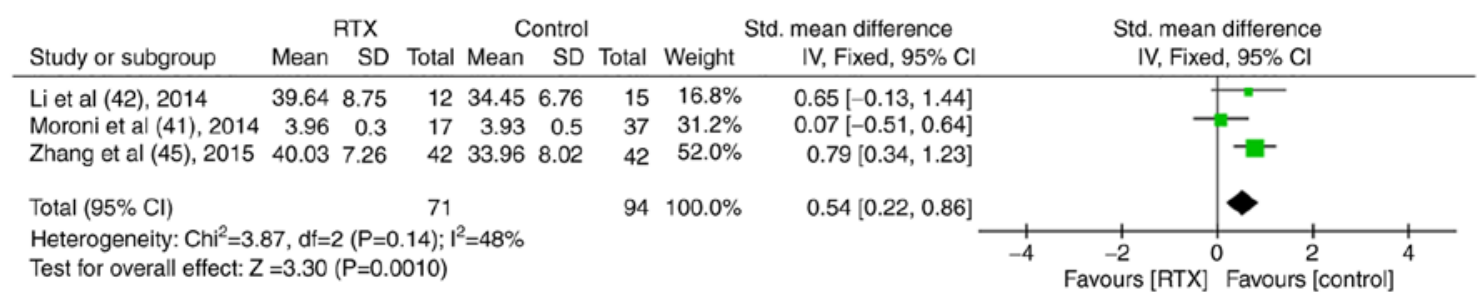

Figure 10. Results of the meta-analysis of serum albumin in patients treated with rituximab in the controlled trials.

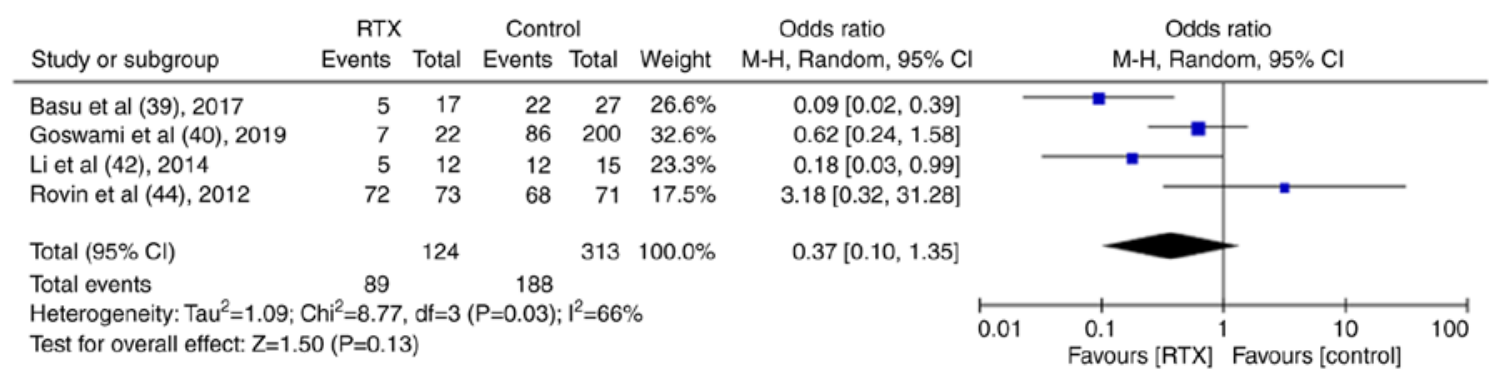

Figure 11. Results of the meta-analysis of adverse events in patients treated with rituximab in the controlled trials.

outcomes of patients with LN following B lymphocyte depletion therapy (51). The aforementioned data indicated that $\mathrm{B}$ lymphocytes played an important role in the incidence and development of LN. B lymphocytes produce antibodies, which in turn form antigen-antibody complexes. These structures deposit in kidney tissues and induce T lymphocyte activation, which in turn is involved in immuno-inflammatory responses.

RTX is a chimeric monoclonal antibody, which specifically targets the CD20 antigen on the surface of B cells. This directly or indirectly eliminates pathogenic B lymphocytes (5). Anolik et al (52) reported that RTX therapy regulated the dysfunction of $B$ lymphocytes and reduced the number of self-reactive memory B lymphocytes for 1 year. Moroni et al (41) examined 54 patients with active LN, which were treated with RTX, MMF or CYC for 12 months; their complete remission rates were $70.6,52.9$ and $65 \%$, respectively, whereas their partial remission rates were 29.4, 41.2 and $25 \%$, respectively. It is worth noting that the patients treated with RTX exhibited more severe LN. However, the majority of the studies regarding the use of RTX for LN were case reports or low-sample size clinical studies. The present meta-analysis assessed the clinical efficacy and safety of RTX for the treatment of LN.

Proteinuria is an independent risk factor for kidney progression. The analysis of six case series and five controlled trials demonstrated that proteinuria markers were significantly decreased following RTX treatment, suggesting that the latter was more effective in treating LN compared with other conventional therapies. RTX exerted increased protective effects against kidney injury compared with traditional immune-suppressants (hormones and/or CYC and MMF), which were consistent with the results from the study by Alshaiki et al (53). Hypoalbuminemia is another manifestation of LN, which is mainly caused by the increased filtration of proteins from the glomeruli compared with their reabsorption and synthesis in the kidney and liver, respectively. The present meta-analysis indicated that treatment of the patients with RTX resulted in a significant increase of their serum albumin levels compared with those of the control group, suggesting that RTX was an effective therapeutic agent for LN.

SLEDAI is a direct method to assess the activity and severity of SLE (54). The present analysis included three case series and five control trials. A significant decrease in SLEDAI was noted following RTX treatment, suggesting that this compound exhibited favorable clinical efficacy in the treatment for LN.

TR and CR varied slightly among different studies, since they were dependent on several factors, such as proteinuria, serum albumin, creatinine and SLEDAI. A total of 30 case series were analyzed and the data indicated that following 
RTX treatment, the parameters TR and the CR were 81.9 and $46.6 \%$, respectively, which was consistent with the results of the study by Zhong et al (55). In addition, seven controlled trials were analyzed and the results indicated that both TR and CR were significantly higher than those of the control group, suggesting that RTX was more effective in the treatment of LN compared with traditional immune-suppressants.

B-lymphocyte depletion can result in significant clinical remission of LN. An enhanced B-cell depletion in LN may result in a more homogenous $\mathrm{B}$-cell depletion profile across participants and increased efficacy in the treatment of LN. The specific correlation analysis between the remission rate of $\mathrm{LN}$ and the degree of B-cell depletion following RTX treatment was not shown in the present study due to limitations of data extraction, different ethnic or racial backgrounds. On the other hand, it was suggested that RTX alone may not deplete B cells sufficiently for the perturbations of LN (56).

The adverse events of RTX mainly included the following: i) Infusion reaction, which occurred often within 1-2 $\mathrm{h}$ following the first intravenous infusion and could be prevented by the prophylactic use of antihistamines or hormones; ii) infection, which may have been associated with the apparent inhibition of B lymphocytes by RTX and the combined use of corticosteroids, CYC, MMF, cyclosporine and other immunosuppressive agents; iii) granulocytopenia, which may be associated with myelosuppression induction by RTX; and iv) photosensitive reactions, which exhibited very low incidence. The membranes or organelles of epidermal cells were damaged by RTX, resulting in adverse events following exposure in ultraviolet radiation. Although RTX treatment was associated with the aforementioned adverse reactions, no significant differences were noted compared with traditional immunosuppressive agents, suggesting that this compound exhibited optimal safety.

The present study has certain limitations which should be mentioned: i) The number of patients included in some studies analyzed was small and the observation time was not consistent across different studies, resulting in a certain degree of error in the estimation of the remission rate; ii) the quality of some included results was low; iii) reports on the recurrence of the disease following RTX treatment for a specific period of time were limited and could not provide sufficient data for statistical comparisons; and iv) publication bias was not included for the selected studies. Therefore, further prospective, larger sample size and high-quality RCT studies are required to further clarify the application timing, optimal usage and dosage, prevention of recurrence and treatment strategies following recurrence. These additional factors may provide guidance for the clinical treatment of LN.

In conclusion, from the present meta-analysis, it was found that RTX exhibited favorable clinical efficacy in the treatment of LN. RTX was more effective in the treatment of LN compared with traditional immunosuppressive therapy (corticosteroids + CYC and/or MMF). In addition, RTX exhibited optimal safety without adverse reactions, such as liver and gonadal damage.

\section{Acknowledgements}

Not applicable.

\section{Funding}

The present study was supported by a grant from the Project of Healthy in Jiangsu Province (no. SS2019055).

\section{Availability of data and materials}

The datasets used and/or analyzed during the current study are available from the corresponding author on reasonable request.

\section{Authors' contributions}

LS contributed to the conception, design and modification of the study. CS and XL reviewed the articles, extracted the data and organized the database search. XL performed the statistical analysis. CS wrote the first draft of the manuscript. GL guided and assisted in the statistical analysis. LZ and JL also contributed to the conception and design of the study. LS, LZ and JL confirm the authenticity of all the data. All authors contributed to manuscript revision, read, and approved the submitted version.

\section{Ethics approval and consent to participate}

Not applicable.

\section{Patient consent for publication}

Not applicable.

\section{Competing interests}

The authors declare that they have no competing interests.

\section{References}

1. Gadakchi L, Hajialilo M, Nakhjavani MR, Abedi Azar S, Kolahi S, Gojazadeh M, Ebrahimi AA, Malek Mahdavi A, Noshad $\mathrm{H}$ and Khabbazi A: Efficacy and safety of mycophenolate mofetil versus intravenous pulse cyclophosphamide as induction therapy in proliferative lupus nephritis. Iran J Kidney Dis 12: 288-292, 2018.

2. Jorge A, Wallace ZS, Zhang Y, Lu N, Costenbader KH and Choi HK: All-cause and cause-specific mortality trends of end-stage renal disease due to lupus nephritis from 1995 to 2014. Arthritis Rheumatol 71: 403-410, 2019.

3. Tedder TF and Engel P: CD20: A regulator of cell-cycle progression of B lymphocytes. Immunol Today 15: 450-454, 1994.

4. Ahuja A, Teichmann LL, Wang H, Dunn R, Kehry MR and Shlomchik MJ: An acquired defect in IgG-dependent phagocytosis explains the impairment in antibody-mediated cellular depletion in Lupus. J Immunol 187: 3888-3894, 2011.

5. Schioppo T and Ingegnoli F: Current perspective on rituximab in rheumatic diseases. Drug Des Devel Ther 11: 2891-2904, 2017.

6. Anderson DR, Grillo-Lo'pez A, Varns C, Chambers KS and Hanna N: Targeted anti cancer therapy using rituximab, a chimaeric anti-CD20 antibody (IDEC-C288)in the treatment of non-Hodgkin's B-cell lymphoma. Biochem Soc Trans 25: 705-708, 1997.

7. Haffner D and Fischer DC: Nephrotic syndrome and rituximab: Facts and perspectives. Pediatr Nephrol 24: 1433-1438, 2009.

8. Dent O: Methodological index for non-randomized studies. ANZ J Surg 73: 675-676, 2003.

9. Clark HD, Wells GA, Huët C, McAlister FA, Salmi LR, Fergusson D and Laupacis A: Assessing the quality of randomized trials: Reliability of the Jadad scale. Control Clin Trials 20: 448-452, 1999. 
10. Boletis JN, Marinaki S, Skalioti C, Lionaki SS, Iniotaki A and Sfikakis PP: Rituximab and mycophenolate mofetil for relapsing proliferative lupus nephritis: A long-term prospective study Nephrol Dial Transplant 24: 2157-2160, 2009.

11. Chavarot N, Verhelst D, Pardon A, Caudwell V, Mercadal L, Sacchi A, Leonardi C, Le Guern V, Karras A and Daugas E: Rituximab alone as induction therapy for membranous lupus nephritis: A multicenter retrospective study. Medicine (Baltimore) 96: e7429, 2017.

12. Contis A, Vanquaethem H, Truchetet ME, Couzi L, Rigothier C, Richez C, Lazaro E and Duffau P: Analysis of the effectiveness and safety of rituximab in patients with refractory lupus nephritis: A chart review. Clin Rheumatol 35: 517-522, 2016.

13. Davies RJ, Sangle SR, Jordan NP, Aslam L, Lewis MJ, Wedgwood R and D'Cruz DP: Rituximab in the treatment of resistant lupus nephritis: Therapy failure in rapidly progressive crescentic lupus nephritis. Lupus 22: 574-582, 2013.

14. Gunnarsson I, Sundelin B, Jónsdóttir T, Jacobson SH, Henriksson EW and van Vollenhoven RF: Histopathologic and clinical outcome of rituximab treatment in patients with cyclophosphamide-resistant proliferative lupus nephritis. Arthritis Rheum 56: 1263-1272, 2007.

15. Hogan J, Godron A, Baudouin V, Kwon T, Harambat J, Deschênes G and Niel O: Combination therapy of rituximab and mycophenolate mofetil in childhood lupus nephritis. Pediatr Nephrol 33: 111-116, 2018.

16. Jónsdóttir T, Zickert A, Sundelin B, Henriksson EW, van Vollenhoven RF and Gunnarsson I: Long-term follow-up in lupus nephritis patients treated with rituximab-clinical and histopathological response. Rheumatology (Oxford) 52: 847-855, 2013

17. Vigna-Perez M, Hernández-Castro $\mathrm{B}$, Paredes-Saharopulos $\mathrm{O}$ Portales-Pérez D, Baranda L, Abud-Mendoza C and González-Amaro R: Clinical and immunological effects of Rituximab in patients with lupus nephritis refractory to conventional therapy: A pilot study. Arthritis Res Ther 8: R83, 2006.

18. Kotagiri P, Martin A, Hughes P, Becker G and Nicholls K: Single-dose rituximab in refractory lupus nephritis. Intern Med J 46: 899-901, 2016

19. Melander C, Sallée M, Trolliet P, Candon S, Belenfant X, Daugas E, Rémy P, Zarrouk V, Pillebout E, Jacquot C, et al: Rituximab in severe lupus nephritis: Early B-cell depletion affects long-term renal outcome. Clin J Am Soc Nephrol 4: 579-587, 2009.

20. Pepper R, Griffith M, Kirwan C, Levy J, Taube D, Pusey C, Lightstone L and Cairns T: Rituximab is an effective treatment for lupus nephritis and allows a reduction in maintenance steroids. Nephrol Dial Transplant 24: 3717-3723, 2009.

21. Sfikakis PP, Boletis JN, Lionaki S, Vigklis V, Fragiadaki KG, Iniotaki A and Moutsopoulos HM: Remission of proliferative lupus nephritis following B cell depletion therapy is preceded by down-regulation of the $\mathrm{T}$ cell costimulatory molecule CD40 ligand: An open-label trial. Arthritis Rheum 52: 501-513, 2005.

22. Iaccarino L, Bartoloni E, Carli L, Ceccarelli F, Conti F, De Vita S, Ferraccioli G, Galeazzi M, Gatto M, Gerli R, et al: Efficacy and safety of off-label use of rituximab in refractory lupus: Data from the Italian Multicentre Registry. Clin Exp Rheumatol 33 449-456, 2015

23. Iwata S, Saito K, Hirata S, Ohkubo N, Nakayamada S, Nakano K, Hanami K, Kubo S, Miyagawa I, Yoshikawa M, et al: Efficacy and safety of anti-CD20 antibody rituximab for patients with refractory systemic lupus erythematosus. Lupus 27: 802-811, 2018.

24. Lateef A, Lahiri M, Teng GG and Vasoo S: Use of rituximab in the treatment of refractory systemic lupus erythematosus: Singapore experience. Lupus 19: 765-770, 2010.

25. Lindholm C, Börjesson-Asp K, Zendjanchi K, Sundqvist AC, Tarkowski A and Bokarewa M: Longterm clinical and immunological effects of anti-CD20 treatment in patients with refractory systemic lupus erythematosus. J Rheumatol 35: 826-833, 2008.

26. Ramos-Casals M, García-HernándezFJ, de Ramón E, Callejas JL, Martínez-Berriotxoa A, Pallarés L, Caminal-Montero L, Selva-O'Callaghan A, Oristrell J, Hidalgo C, et al: Off-label use of rituximab in 196 patients with severe, refractory systemic autoimmune diseases. Clin Exp Rheumatol 28: 468-476, 2010.

27. Arce-Salinas CA, Rodriguez-Garcia F and Gomez-Vargas JI: Long-term efficacy of anti-CD20 antibodies in refractory lupus nephritis. Rheumatol Int 32: 1245-1249, 2012.

28. Catapano F, Chaudhry AN, Jones RB, Smith KG and Jayne DW: Long-term efficacy and safety of rituximab in refractory and relapsing systemic lupus erythematosus. Nephrol Dial Transplant 25: 3586-3592, 2010.
29. Condon MB, Ashby D, Pepper RJ, Cook HT, Levy JB, Griffith M, Cairns TD and Lightstone L: Prospective observational single-centre cohort study to evaluate the effectiveness of treating lupus nephritis with rituximab and mycophenolate mofetil but no oral steroids. Ann Rheum Dis 72: 1280-1286, 2013.

30. Garcia-Carrasco M, Mendoza-Pinto C, Sandoval-Cruz M, Soto-VegaE, Beltran-Castillo A,Jimenez-Hernandez M,Graillet D, Gonzalez L, Rojas-Rodriguez J, Pineda-Almazana A, et al: Anti-CD20 therapy in patients with refractory systemic lupus erythematosus: A longitudinal analysis of 52 Hispanic patients. Lupus 19: 213-219, 2010.

31. Bang SY, Lee CK, Kang YM, Kim HA, Suh CH, Chung WT, Park YB, Choe JY, Kim TJ, Park YW, et al: Multicenter retrospective analysis of the effectiveness and safety of rituximab in korean patients with refractory systemic lupus erythematosus. Autoimmune Dis 2012: 565039, 2012.

32. Tanaka Y, Takeuchi T, Miyasaka N, Sumida T, Mimori T, Koike T, Endo K, Mashino N and Yamamoto K: Efficacy and safety of rituximab in Japanese patients with systemic lupus erythematosus and lupus nephritis who are refractory to conventional therapy. Mod Rheumatol 26: 80-86, 2016.

33. Tsanyan ME, Soloviev SK, Radenska-Lopovok SG, Torgashina AV, Nikolaeva EV, Khrennikov YB and Nasonov EL: Clinical and morphological improvement of lupus nephritis treated with rituximab. Folia Med (Plovdiv) 56: 245-252, 2014.

34. Terrier B, Amoura Z, Ravaud P, Hachulla E, Jouenne R, Combe B, Bonnet C, Cacoub P, Cantagrel A, de Bandt M, et al: Safety and efficacy of rituximab in systemic lupus erythematosus: Results from 136 patients from the French AutoImmunity and Rituximab registry. Arthritis Rheum 62: 2458-2466, 2010.

35. Chen J: Clinical efficacy and safety of low-dose rituximab combined with glucocorticoid in children with lupus nephritis. J Trauma Emergency 6, 2018

36. Qiu ML, Jin O, Fang LK: Analysis of the Effect of small dose of rituximab in the treatment of systemic lupus erythematosus. China Foreign Medical Treatment 32, 2013.

37. Su GX, Wu FQ, Wang F, Zhou ZX, Huang XL and Lu J: Rituximab therapy for severe pediatric systemic lupus erythematosus. Zhonghua Er Ke Za Zhi 50: 697-704, 2012 (In Chinese).

38. Fan ZY, Cai YB, Gu YY, Yang CD, Bao CD and Ye S: Efficacy of rituximab in patients with refractory severe systemic lupus erythematosus. Chin Remedies Clin 9, 2009.

39. Basu B, Roy B and Babu BG: Efficacy and safety of rituximab in comparison with common induction therapies in pediatric active lupus nephritis. Pediatr Nephrol 32: 1013-1021, 2017.

40. Goswami RP, Sircar G, Sit H, Ghosh A and Ghosh P: Cyclophosphamide versus mycophenolate versus rituximab in lupus nephritis remission induction: A historical Head-to-Head comparative study. J Clin Rheumatol 25: 28-35, 2019.

41. Moroni G, Raffiotta F, Trezzi B, Giglio E, Mezzina N, Del Papa N, Meroni P, Messa P and Sinico AR: Rituximab vs mycophenolate and vs cyclophosphamide pulses for induction therapy of active lupus nephritis: A clinical observational study. Rheumatology (Oxford) 53: 1570-1577, 2014

42. Li L, Luo FZ, Deng ZP and Wu BY: Application of rituximab in the treatment of severe and refractory lupus nephritis. J Nanjing Medical University (Natural Science edition) 34, 2014.

43. Wu SH: Clinical efficacy of rituximab in the treatment of severe lupus nephritis. Road to Health 9, 2019.

44. Rovin BH, Furie R, Latinis K, Looney RJ, Fervenza FC, Sanchez-Guerrero J, Maciuca R, Zhang D, Garg JP, Brunetta $\mathrm{P}$, et al: Efficacy and safety of rituximab in patients with active proliferative lupus nephritis: The lupus nephritis assessment with rituximab study. Arthritis Rheum 64: 1215-1226, 2012.

45. Zhang J, Zhao Z and Hu X: Effect of rituximab on serum levels of Anti-Clq and antineutrophil cytoplasmic autoantibodies in refractory severe lupus nephritis. Cell Biochem Biophys 72: 197-201, 2015.

46. Fanouriakis A, Kostopoulou M, Alunno A, Aringer M, Bajema I, Boletis JN, Cervera R, Doria A, Gordon C, Govoni M, et al: 2019 update of the EULAR recommendations for the management of systemic lupus erythematosus. Ann Rheum Dis 78: 736-745, 2019.

47. Tektonidou MG, Dasgupta A and Ward MM: Risk of End-Stage renal disease in patients with lupus nephritis, 1971-2015: A systematic review and Bayesian Meta-Analysis. Arthritis Rheumatol 68: 1432-1441, 2016.

48. Yap DYH and Chan TM: B Cell abnormalities in systemic lupus erythematosus and lupus nephritis-role in pathogenesis and effect of immunosuppressive treatments. Int J Mol Sci 20: 6231, 2019. 
49. Cassia M, Alberici F, Gallieni M and Jayne D: Lupus nephritis and B-cell targeting therapy. Expert Rev Clin Immunol 13: 951-962, 2017.

50. Sun CY, Shen Y, Chen XW, Yan YC and Yang CD: Distribution and significance of B-cell infiltrates in lupus nephritis. Chin J Rheumatol 15, 2011.

51. Jónsdóttir T, Gunnarsson I, Mourão AF, Lu TY, van Vollenhoven RF and Isenberg D: Clinical improvements in proliferative vs membranous lupus nephritis following B-cell depletion: Pooled data from two cohorts. Rheumatology (Oxford) 49: 1502-1504, 2010.

52. Anolik JH, Campbell D, Felgar RE, Young F, Sanz I, Rosenblatt J and Looney RJ: The relationship of FcgammaRIIIa genotype to degree of B cell depletion by rituximab in the treatment of systemic lupus erythematosus. Arthritis Rheum 48: 455-459, 2003.
53. Alshaiki F, Obaid E, Almuallim A, Taha R, El-Haddad $\mathrm{H}$ and Almoallim H: Outcomes of rituximab therapy in refractory lupus: A meta-analysis. Eur J Rheumatol 5: 118-126, 2018.

54. Gladman DD, Ibañez D and Urowitz MB: Systemic lupus erythematosus disease activity index 2000. J Rheumatol 29: 288-291, 2020.

55. Zhong Z, Li H, Zhong $\mathrm{H}$ and Zhou T: Clinical efficacy and safety of rituximab in lupus nephritis. Drug Des Devel Ther 13: 845-856, 2019

56. Stolyar L, Lahita RG and Panush RS: Rituximab use as induction therapy for lupus nephritis: A systematic review. Lupus 29: 892-912, 2020.

This work is licensed under a Creative Commons Attribution-NonCommercial-NoDerivatives 4.0 International (CC BY-NC-ND 4.0) License. 